\title{
High Temperature Gold Deposition from Acid Cyanide Baths
}

\author{
DEVELOPMENT OF ELECTROLYTES FOR THE LASER-ENHANCED ELECTRODEPOSITION \\ OF GOLD
}

\author{
Christoph J. Raub, Hamind R. Khan and Manfred Baumgärtner \\ Forschungsinstitut für Edelmetalle und Metallchemie, Schwäbisch Gmünd, Federal Republic of Germany
}

\begin{abstract}
To simulate some of the conditions wbich prevail in laserenbanced electrodeposition (LEE) of gold from three acid cyanide baths, containing cobalt, nickel and iron respectively, gold plating was conducted at elevated temperatures and pressures. It was found that almost pure gold deposits were formed which were similar to deposits obtained from the baths by LEE. Experiments of this type produce deposits of relatively larger surface areas, which are more suitable for analysis, than deposits obtained by LEE. It is suggested that this simulation system may be useful in developing electrolytes suitable for use in $\mathrm{LEE}$.
\end{abstract}

In laser-enhanced electrodeposition (LEE) of gold, metal deposition occurs preferentially from electrolyte which is locally heated to temperatures of $100^{\circ} \mathrm{C}$ or higher as a result of the laser-irradiation of the substrate surface. This situation has no parallel in conventional plating. In this article, we report preliminary results from studies of gold deposition at similar elevated temperatures but without laser irradiation of the cathode. The baths studied were $\mathrm{Au} / \mathrm{Co}, \mathrm{Au} / \mathrm{Ni}$ and $\mathrm{Au} / \mathrm{Fe}$ acid cyanide baths of the type used for the conventional production of bright hard deposits. In the temperature range of LEE $\left(\geqslant 100^{\circ} \mathrm{C}\right)$ the codeposition of other metals and of non metals from these baths dropped greatly, thereby affecting the hardness and surface structure of the deposits. It is concluded that if deposits with specified properties are to be obtained in laserenhanced plating of gold, electrolytes must be specially developed for the purpose. In the screening of electrolytes for this purpose, deposition from them at elevated temperatures by the method developed for this study may well prove rewarding.

Heating of the electrolyte at the interface between it and the cathode, leading to localised electrolyte temperatures as high as $120^{\circ} \mathrm{C}$, is a highly significant factor in the LEE of metals. A number of publications (1-4) has appeared in which the effects of this localised heating of the electrolyte on the mechanism of electrodeposition have been discussed.

The small size of the deposits from LEE makes it difficult to study their properties. This explains why virtually no information has been published so far about physical and chemical properties such as the chemical composition, hardness and resistance to wear of the electrodeposits formed under these conditions. The chemical composition and structure of the deposited metal, which determine its other properties, are particularly important for applications of laser enhanced plating.
In an earlier study (4), however, in which measurements were made on deposits using energy dispersive X-ray analysis (EDAX) in the scanning electron microscopy (SEM), it was found that the deposits obtained by LEE from a gold/cobalt acid cyanide bath of the normal type were virtually cobalt-free, in contrast to those obtained under conventional conditions. In the case of deposits from gold/nickel acid cyanide baths, similar studies showed that codeposition of nickel with the gold during LEE was not greatly affected.

Since the extent to which cobalt and nickel are codeposited with the gold determines, to a large measure, the functional properties of the respective deposits $(5,6)$, it became apparent that a more detailed study of the codeposition of other elements with gold from these and other electrolytes, under conditions of laser-enhancement, was of special importance.

One possible approach to this problem is to simulate temperature conditions of laser-enhanced plating. This can be done by conducting the plating operation in an autoclave at increased temperature and pressure. Although it did not seem possible to simulate other factors such as, the microconvection effects of the boiling electrolyte under laser-enhanced conditions, nevertheless we decided to proceed with a series of autoclave studies of gold plating. These were carried out at various temperatures up to $160^{\circ} \mathrm{C}$ ( 5 bar).

In this manner, coatings were formed several square centimetres in area and up to several micrometres in thickness, according to the electrolyte used. Copper and silver sheets were used as substrates. Tests carried out on the coatings included chemical analysis, determinations of ductility, resistance to wear and hardness, and X-ray, metallographic and scanning electron microscopic examinations.

This publication is limited to an account of some of the results of initial experiments using gold/cobalt, gold/nickel and 
gold/iron acid cyanide plating baths at plating temperatures up to $160^{\circ} \mathrm{C}$. The equipment developed for the autoclave studies will not be described here. These baths are widely used in the selective plating of connectors, and are of potential importance in laser-enhanced gold plating. Their selection for study is also appropriate since the compositions and properties of the coatings obtained from them under normal plating conditions have been studied intensively, and hence data are available for comparison purposes.

\section{Results and Discussions}

In all the three types of baths, deposition was from a $250 \mathrm{ml}$ bath at $\mathrm{pH} 3.5$, using a current density of $1 \mathrm{~A} / \mathrm{dm}^{2}$. The substrates were copper or silver sheets. Freshly prepared electrolyte was used in each experiment.

\section{Deposits from a Gold/Cobalt Bath}

Since earlier detailed studies (7-9) of deposits from baths of this type under normal conditions were made using weak acid gold(I) cyanide electrolyte buffered with citrate, this type of gold/cobalt bath was selected for use. Its composition is set out in Figure 1.

Figure 1 illustrates the variation in the cobalt content of the electrodeposits with bath temperature. The values plotted are average values from two series of experiments. In agreement with the results of the earlier studies (9), the cobalt contents of deposits at $40^{\circ} \mathrm{C}$ were in the range 0.3 to $0.5 \%$. These earlier studies indicated a trend towards lower cobalt content with increasing temperature. However, the results of the present study show that with increasing temperature the cobalt contents of the deposits first increased to a maximum of 0.8 to 1.0 per cent at about $80^{\circ} \mathrm{C}$, and then dropped sharply between 100 and $120^{\circ} \mathrm{C}$ to about 0.1 per cent. Above $120^{\circ} \mathrm{C}$ the cobalt contents of deposits were very low so that the coatings were virtually pure gold.

From the current efficiency - temperature diagram (Figure 8) it will be noted that a weak minimum in current efficiency occurs over the temperature range of $60^{\circ} \mathrm{C}$ to $80^{\circ} \mathrm{C}$ over which the cobalt content of the deposits is a maximum. At higher temperatures the current efficiency increases gradually and reaches 100 per cent at $160^{\circ} \mathrm{C}$, which is about $40^{\circ} \mathrm{C}$ higher than the temperature at which the cobalt content of the deposits is significantly below $0.1 \%$. Between 120 and $160^{\circ} \mathrm{C}$, a second cathodic reaction must be taking place in addition to gold deposition. The same effect was observed in three series of experiments using both gold/cobalt and gold/nickel electrolytes, and at this stage no full explanation of it can be given. More extensive studies, which are in progress on the percentages of hydrogen, oxygen and nitrogen and on the relative percentages of complexed and total cobalt in the deposits, may throw light on the matter. Preliminary measurements of carbon

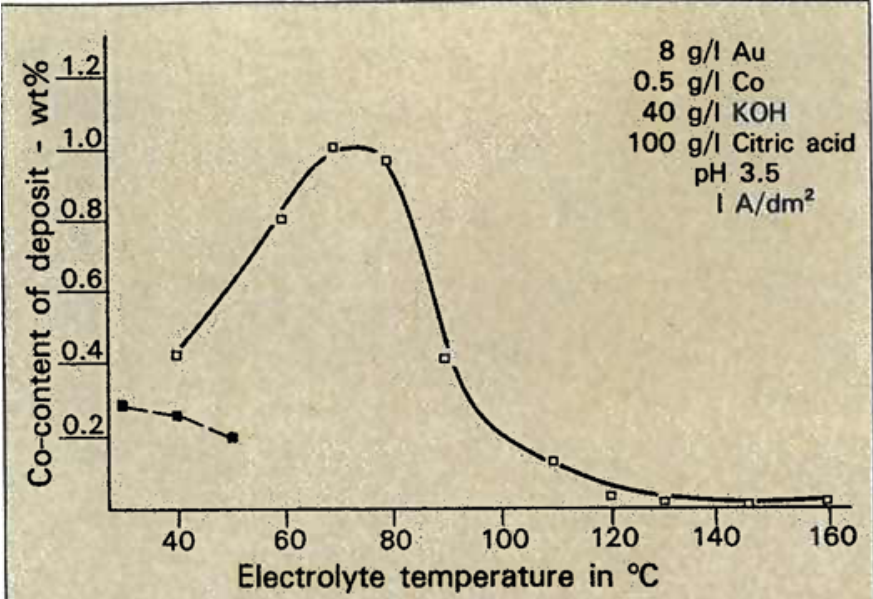

Fig. 1 Variation of the cobalt content of the gold-cobalt deposits with electrolyte temperature. Solid blocks refer to previous results (9)

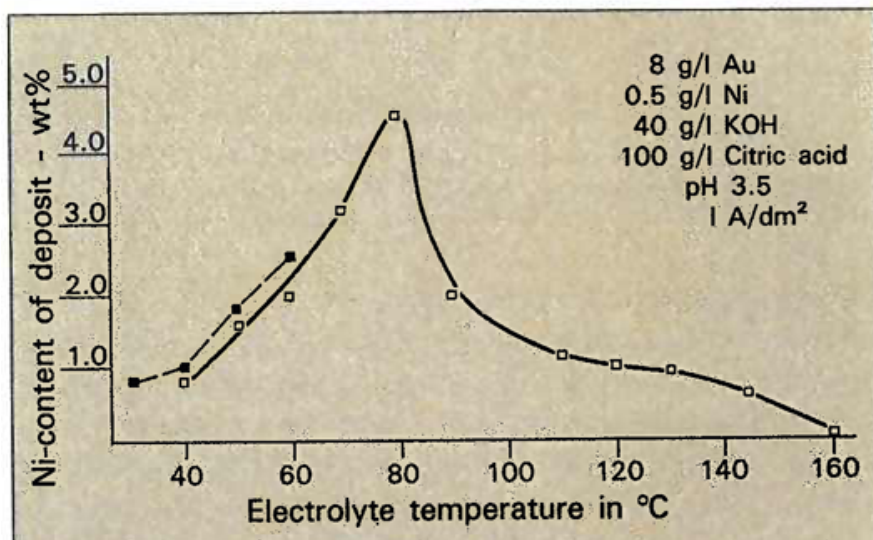

Fig. 2 Variation of the nickel content of the gold-nickel deposits with electrolyte temperatures. Solid blocks refer to previous results (8)

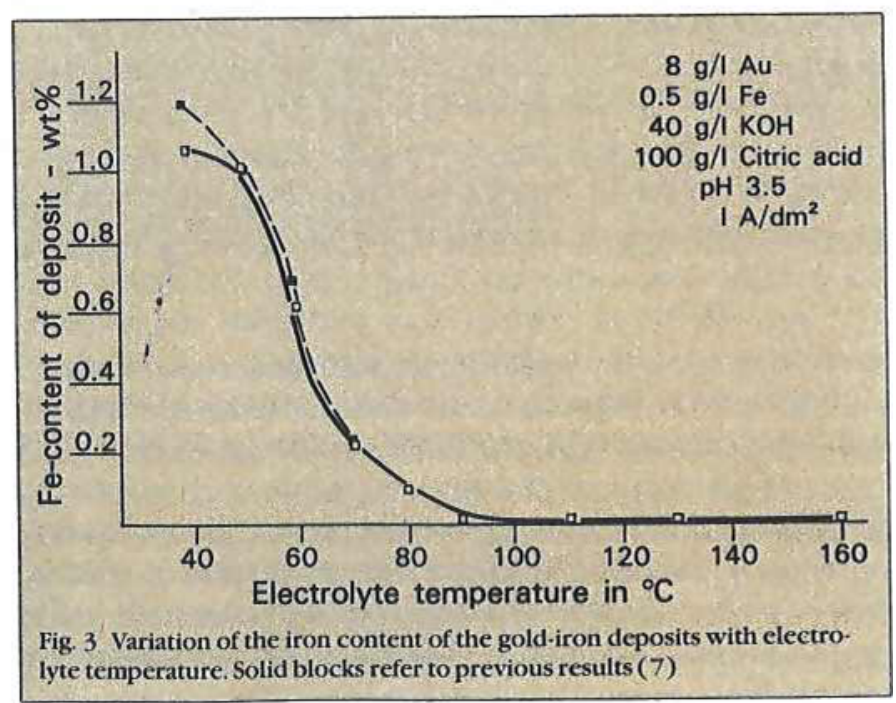




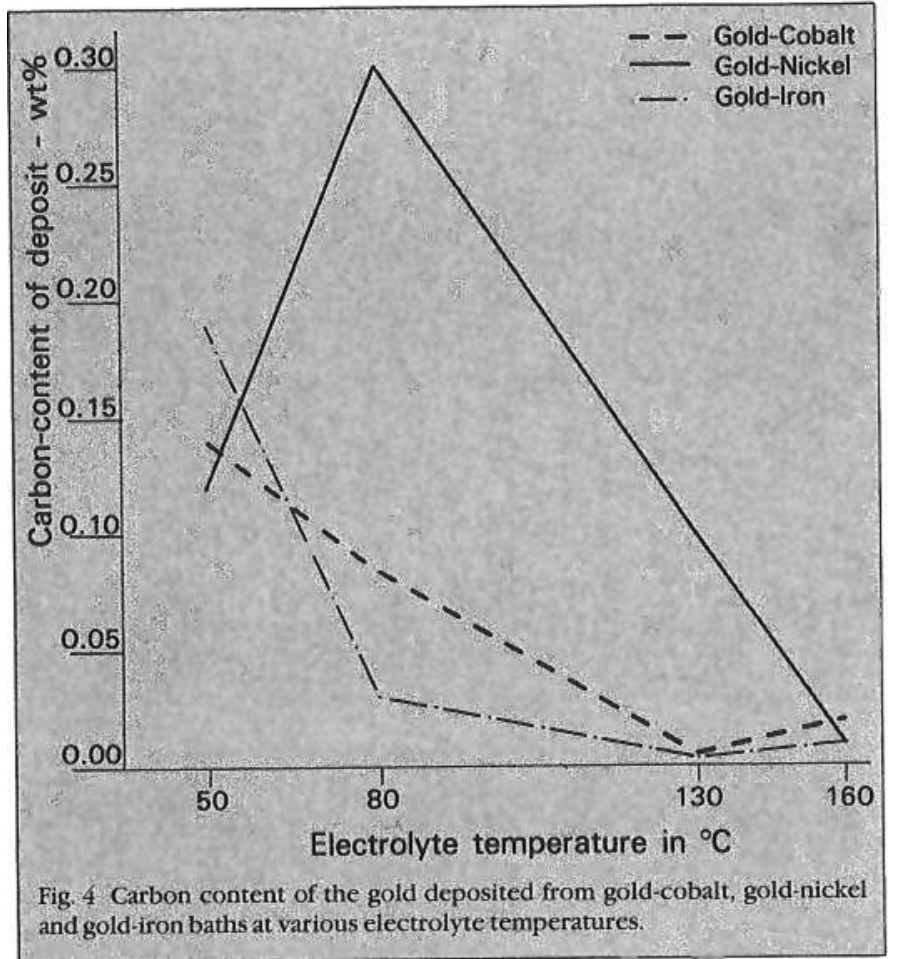

contents indicated that these had minimum values of 0.005 to 0.006 per cent in coatings from gold/cobalt and gold/iron electrolytes between about 100 and $120^{\circ} \mathrm{C}$ (Figure 4). In deposits from gold/nickel electrolytes, the contents were higher.

The hardness of the deposits changed roughly in parallel with the variations in their total cobalt contents. Coatings deposited above $90^{\circ} \mathrm{C}$ had HV10 hardnesses of only 100 . Almost certainly, increasing healing of lattice defects plays a role in determining the hardnesses of coatings deposited at higher temperatures. The structures of the coatings as observed by SEM are in accord with their optical appearance. Deposits formed from below 100 to $120^{\circ} \mathrm{C}$ are still bright and yellow, but those formed above $120^{\circ}$ are increasingly matt brown in appearance. At the same time the surface structure altered from smooth (Figure 5) to coarsely crystalline (Figure 6). This latter surface structure corresponds with that of gold and palladium coatings obtained by laser enhanced plating (Figure 7) (Figure 16 in (4)) and with that of coatings from gold/nickel and gold/iron electrolytes produced at similar temperatures.

The similarity between the structures of coatings deposited with laser-enhancement and those of coatings formed at elevated temperatures in the autoclave confirms the dominant role of local electrolyte temperature in laser-enhanced plating. It supports the hypothesis that the properties of coatings formed from gold/cobalt electrolytes by laser-enhanced and by 'autoclave' plating at suitable elevated temperatures should be comparable.

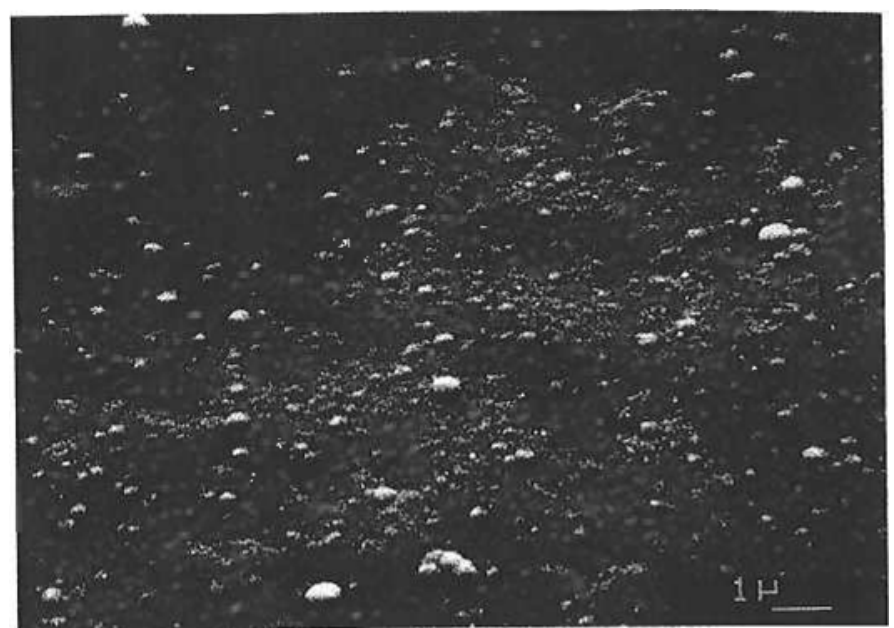

Fig. 5 Scanning electron micrograph of the surface of a gold-cobalt coating containing $0.35 \%$ cobalt deposited at $40^{\circ} \mathrm{C}$.

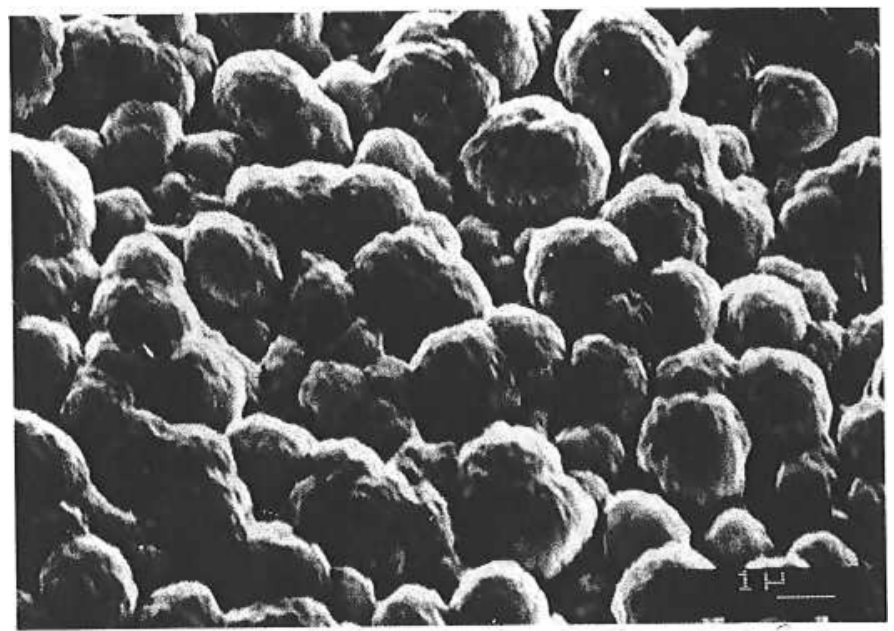

Fig. 6 Scanning electron micrograph of the surface of a gold-cobalt coating containing $0.02 \%$ cobalt deposited at $160^{\circ} \mathrm{C}$.

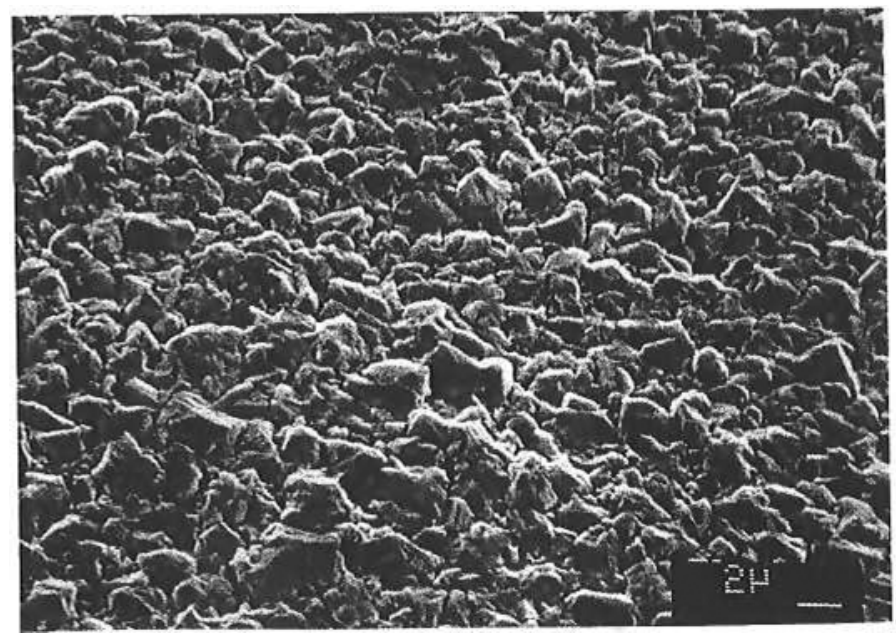

Fig. 7 Scanning electron micrograph of the surface of a gold coating formed by laser-enhanced electrodeposition. 


\section{Deposits from a Gold/Nickel Bath}

The composition of the bath and the variations in the average values of the nickel contents of deposits obtained in two series of experiments are shown in Figure 2. Agreement with the results of earlier studies (8) of deposits formed below $60^{\circ} \mathrm{C}$ is very good.

On account of relatively weaker complex formation by nickel, the contents of nickel in the deposits are greater by a factor of 4 to 5 than the contents of cobalt and iron observed in similar experiments.

A fall in base metal content, similar to that observed with deposits from gold/cobalt baths, occurs above $80^{\circ} \mathrm{C}$ but takes place much more gradually. Thus at $140^{\circ} \mathrm{C}$, at which temperature the gold/cobalt bath produces deposits with 0.02 per cent cobalt, the gold/nickel bath produces deposits containing 0.8 per cent nickel

The rise in the current efficiency/temperature curve (Figure 8 ) is virtually identical with that observed using the gold/cobalt bath. The minimum in the current efficiency is also at about the temperature at which the base metal content of the deposit is a maximum $\left(\mathrm{ca} .80^{\circ} \mathrm{C}\right)$.

Although the nickel contents of the deposits fall more gradually above this temperature than do the cobalt contents of deposits from gold/cobalt baths, the current efficiencies increase with temperatures in an almost identical manner.

With increasing electrolyte temperatures, not only do the nickel contents of the deposits decrease, but also their carbon contents below $60^{\circ} \mathrm{C}$ and above $100^{\circ} \mathrm{C}$, with a maximum in the C-values at $80^{\circ} \mathrm{C}$ (Figure 4 ).

In accord with their relatively higher concentrations of base metal, electrodeposits from gold/nickel baths are harder (see Figure 9) than those obtained from gold/cobalt and gold/iron electrolytes under similar conditions. Moreover, they decrease in hardness more slowly with increase in deposition tempera ture than coatings from these latter electrolytes.

A maximum of 300 in the HV10 hardness of the deposited gold is observed near $80^{\circ} \mathrm{C}$ (Figure 9), which is the temperature at which the maximum amount of nickel is plated out with the gold (Figure 2). Only at $160^{\circ} \mathrm{C}$, when their contents of base metal in the deposits all approach zero, do the hardnesses of the deposits from the three baths fall to similar values (ca.100 HV).

In preliminary SEM studies, the surface structures of deposits from the gold/nickel bath were found to be similar to those from gold/cobalt and gold/iron baths. At $160^{\circ} \mathrm{C}$ the same structure, namely that shown in Figure 6 for a deposit from the gold/cobalt baths, was observed in deposits from the gold/ nickel bath
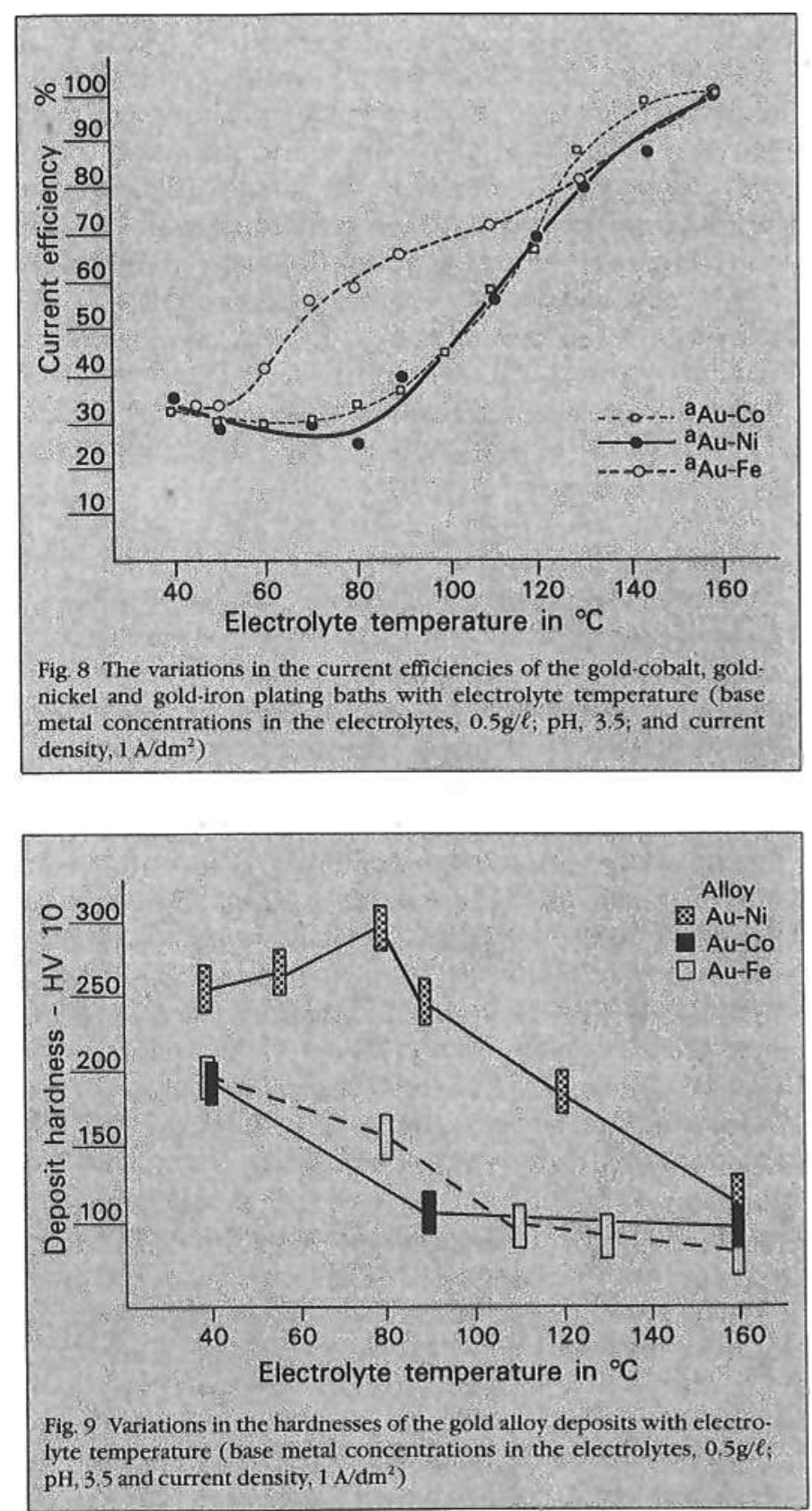

\section{Deposits from a Gold/Iron Bath}

The bath composition is listed in Figure 3. The deposits differ considerably. from those obtained from gold/cobalt and gold/nickel baths in that they exhibit no maximum in their content of iron as the deposition temperature is increased. In agreement with the results of earlier studies (7), a steep decrease is observed in their contents of iron as the temperature is increased (Figure 3), and above $100^{\circ} \mathrm{C}$ almost iron-free gold is deposited. At this temperature also, the carbon content of the 
deposits has decreased to less than 0.02 per cent (Figure 4). In accord with the steady. fall in the iron-content of the deposits, the current efficiency of gold deposition increases steadily with deposition temperature to as high as 100 per cent at about $160^{\circ} \mathrm{C}$ (Figure 8). The change in the gradient of the current efficiency/deposition temperature curve at about $80^{\circ} \mathrm{C}$, which occurs with gold/cobalt and gold/nickel baths, is not observed.

The hardness of deposits from the gold/iron electrolyte falls rapidly with deposition temperature as is the case with deposits from the gold/cobalt bath (Figure 9).

The appearance of the gold/iron coatings, by SEM examination, was similar to that (Figures 5 to 7 ) of gold/cobalt and gold/nickel coatings.

\section{Summary and Discussion}

Three weakly acid bright gold plating baths have been investigated and the variations in the current efficiencies of gold deposition and in the composition, hardness and structure of the deposits have been established over a temperature range of 40 to $160^{\circ} \mathrm{C}$. The baths studied were a gold/cobalt, gold/nickel and a gold/iron bath, and it was found that with each of them the codeposition of base metal, and other impurities, with the gold decrease at temperatures above $80^{\circ} \mathrm{C}$. The $\mathrm{C}$ in the Au-Ni system forms an exception. There were only minor differences between the baths in this respect. As a result, the properties of the deposits formed btween 80 and $160^{\circ} \mathrm{C}$ from all three baths differed greatly from those of deposits formed at lower temperatures.

Specifically, the current efficiencies of gold deposition increased by a factor of approximately three under conditions of accelerated deposition, rising from about 35 per cent at $35^{\circ} \mathrm{C}$, to 70 per cent at $120^{\circ} \mathrm{C}$, and to 100 per cent at $160^{\circ} \mathrm{C}$. Between $80^{\circ} \mathrm{C}$ and $120^{\circ} \mathrm{C}$, the percentage nickel in the deposits from the gold/nickel bath fell from about 4.5 per cent to 1 per cent, the percentage cobalt in the deposits from the gold/cobalt bath fell from about 1 per cent to under 0.1 per cent, and the percentage iron in the deposits from the gold/iron baths fell from about 1 per cent to under 0.1 per cent. From all three baths, the deposits at $160^{\circ} \mathrm{C}$ were essentially pure gold.

As regards hardness, the changes were equally impressive At $120^{\circ} \mathrm{C}$, the deposits from the gold/cobalt and gold/iron baths had HV10 hardnesses which were virtually the same as that of pure gold. In accord with their higher base metal contents between $80^{\circ} \mathrm{C}$ and $120^{\circ} \mathrm{C}$, however, the deposits from the gold/ nickel bath had hardnesses which fell more slowly with temperature, and reached the figure for pure gold only near $160^{\circ} \mathrm{C}$

\section{Conclusions}

These studies cover the range of temperatures $\left(100-120^{\circ} \mathrm{C}\right)$ over which electrodeposition takes place in laser-enhanced plating of gold. They emphasise the extent to which the high electrolyte temperatures, which prevail at the interface with the substrate during this type of plating, can influence the properties and compositions of the deposits which it yields. As a corollary, it must be concluded that if gold coatings with specified properties are to be produced by this new plating technique, electrolytes will have to be developed specially for the purpose.

In view of the difficulties inherent in using laser enhancement for the production of deposits which are large enough for determination of their properties by conventional methods, it is suggested that the behaviour of electrolytes under evaluation be tested at elevated temperatures by the methods exemplified. Although such testing does not simulate all the conditions under which deposition occurs in laser-enhanced plating, experience such as has been recorded above should facilitate interpretation of the results obtained, and provide an improved basis for the extended application of laser-enhanced electrodeposition of gold.

Acknowledgements: The authors thank Dr. W.S. Rapson for his assistance in preparing the manuscript. The work was supported by the A.I.F. (Arbeitsgemeinschaft Industrielle Forschungsvereinigungen, Cologne) from funds of the BMWi (Bundeswirtschaftsministeriums für Wirtschaft).

\section{References}

1 R.J. von Gutfeld, R.L. Melcher, E.E. Tynan and S.E. Blum, Appl. Pbys. Lett., $1979,35,651-653$

2 R.J. von Gutfeld and J. Cl. Puippe, Oberfläche - Surface, 1981, 22, 294-298

3 R.J. von Gutfeld and L.T. Romankiw, Gold Bull., 1982, 15, (4), 120-123

4 F. Freidrich and Ch. J. Raub, Metalloberfläcbe, 1984, 38, 237-242
5 R. De Doncker and J. Vanhumbeeck, Trans. Inst. Met. Finish., 1985, 62, $59-63$

6 A. Knödler, Metalloberfläcbe, 1974, 28, 465-472

7 A. Knödler, Metalloberfläche, 1984, 38, 539-546

8 A. Knödler, Galvanotechnik, 1977, 68, (5), 383-391

9 Ch.J. Raub. A. Knödler and J. Lendray, Plating, 1976, 63, 35-40 